\title{
IL-18 and IL-35 in the serum of patients with sepsis thrombocytopenia and the clinical significance
}

\author{
MEIRONG ZHU, XIAOQIAN RONG, MIN LI and SHAOQIN WANG \\ Department of Critical Care Medicine, Jinan Central Hospital Affiliated to Shandong University, \\ Jinan, Shandong 250013, P.R. China
}

Received June 27, 2019; Accepted November 11, 2019

DOI: $10.3892 /$ etm.2019.8347

\begin{abstract}
Expression levels of interleukin-18 (IL-18) and IL-35 in the serum of patients with sepsis and without thrombocytopenia and patients with sepsis thrombocytopenia (TCP) were detected to preliminarily investigate their clinical significance. One hundred and sixty-six patients admitted to Jinan Central Hospital Affiliated to Shandong University from July 2013 to September 2015 were retrospectively analysed. There were 96 patients with sepsis without thrombocytopenia in the sepsis group, and 70 patients with sepsis TCP in the sepsis TCP group. In the same period, 80 healthy subjects were selected as the control group. Fluorescent quantitative PCR was used for the detection the expression of mRNA levels of IL-18 and IL-35, and Enzyme-linked immunosorbent assay for the detection of the protein concentrations of IL-18 and IL-35 in the serum of peripheral blood. The correlation between IL-18, IL-35 and platelets was analyzed. There were significant differences in albumin, creatinine, total bilirubin and platelet count between the sepsis group and the sepsis TCP group $(\mathrm{P}<0.05)$; the expression levels of mRNA of IL-18 and IL-35 in a karyocyte in peripheral blood in the sepsis group and the sepsis TCP group were higher than those in the control group $(\mathrm{P}<0.05)$; the expression of mRNA of IL-18 and IL-35 in the sepsis TCP group was higher than those in the sepsis group $(\mathrm{P}<0.05)$. The concentration of IL-18 and IL-35 in the sepsis TCP group was higher than in the sepsis group $(\mathrm{P}<0.05)$; IL-18 and IL-35 were negatively correlated with platelets $(\mathrm{r}=-0.8749,-0.6228, \mathrm{P}<0.001)$. There was a significant positive correlation between serum IL-18 and IL-35 in the control group, sepsis group, and sepsis TCP group $(\mathrm{r}=0.5124,0.5718$, $0.5511, \mathrm{P}<0.001)$. IL-18 and IL-35 were negatively correlated with the reduced degree of platelets in patients with sepsis
\end{abstract}

Correspondence to: Dr Shaoqin Wang, Department of Critical Care Medicine, Jinan Central Hospital Affiliated to Shandong University, 105 Jiefang Road, Jinan, Shandong 250013, P.R. China E-mail: qiop25@163.com

Key words: IL-18, IL-35, sepsis, sepsis thrombocytopenia, platelet and are likely to play an important role in the pathogenetic process of sepsis TCP.

\section{Introduction}

Sepsis refers to hosts' uncontrolled immune response to infection, which in turn affects organ functions and causes death of critically ill patients; it is also one of the main problems in the global health care system (1-3). Pathogenesis of sepsis is extremely complex and has not yet been fully clarified (4). Data show that the decrease of platelets occur in 35 to $59 \%$ of patients with sepsis. It was found that the symbolic risk factor of the death of patients with sepsis is thrombocytopenia (TCP), which is induced by infections, and the recovery of the minimum value of platelet count is associated with the decrease of mortality (5-7). Studies have shown that when patients are stimulated by endotoxin, platelet activation can be induced by some pathways, which makes platelets play an important role and induce the body to produce an immune response $(8,9)$.

Interleukin-18 (IL-18), a general pro-inflammatory cytokine, is widely distributed in the body, and it can facilitate the production of interferon- $\gamma(\mathrm{IFN}-\gamma)$ and regulate the initial immune response of infection and inflammation (10). Studies have found that the severity and prognosis of sepsis are closely related to IL-18 $(11,12)$. IL-35 is produced by regulatory $\mathrm{T}$ cells and is related to occurrence and progression of a variety of diseases; it is mainly involved in immune response, autoimmune diseases, infections and inflammation, as a new inflammatory factor, IL-35 can be used as a promising therapeutic target $(13,14)$. Recent studies have shown that IL-35 can effectively improve infectious diseases and delay the development of the immune inflammatory response caused by itself, and infections can promote Treg and other cells to secrete more IL-35, which enhances the body's tolerance to inflammatory response caused by infections (15). Therefore, it has been speculated that IL-18 and IL-35 are involved in sepsis TCP. However, there are currently few studies on the expression of IL-18 and IL-35 and the correlation between them and thrombocytopenia in patients with sepsis TCP.

In this study, the expression of IL-18 and IL-35 in the serum and in karyocytes in peripheral blood of patients with sepsis and patients with sepsis TCP were studied, and the correlation between IL-18, IL-35 and platelet and their clinical significance were investigated. 


\section{Patients and methods}

General data. In total, 166 patients who were admitted to Jinan Central Hospital Affiliated to Shandong University (Jinan, China) from July 2013 to September 2015 were collected, and they conformed to the diagnostic criteria of sepsis developed by the American College of Critical Care Medicine in 2001 (16). Among them, 96 patients who had sepsis without thrombocytopenia were the sepsis group; there were 55 males and 41 females, aged $65.12 \pm 8.11$ years. Seventy patients with sepsis TCP were the sepsis TCP group; there were 45 males and 25 females, aged $66.21 \pm 10.12$ years. Eighty healthy subjects were selected as the control group, aged $64.20 \pm 6.81$ years, including 49 males and 31 females.

Inclusion criteria: Patients who did not have unhealty habits; patients wgo actively cooperated with the treatment; patients with complete clinicopathological data; patients with sepsis caused by different pathogen infections (G-bacteria, $\mathrm{G}^{+}$bacteria, fungi and no-bud anaerobic bacteria) and met the latest diagnostic criteria for sepsis; patients with peripheral blood platelet count $\leq 50 \times 10^{9} / 1$ (the criterion for TCP).

Exclusion criteria: Patients in gestation period or puerperium; patients under the age of 18 years; patients had diseases which affected the formation of platelet, such as primary thrombocytosis; patients who had a history of malignancy in blood system; patients with decompensated cirrhosis or failure; patients who had history of chemotherapy; patients who received therapeutic anticoagulation or blood transfusion in the prior four weeks; patients died within $24 \mathrm{~h}$ after they were hospitalized.

This study was approved by the Ethics Committee of Jinan Central Hospital Affiliated to Shandong University, and the experimental content relating to the patients was described in detail. The patients and their families agreed and signed an informed consent form.

The collection of samples. Sequential organ failure assessment (SOFA) and acute physiology and chronic health evaluation (APACHE II) were carried out for all the patients within $24 \mathrm{~h}$ after they were hospitalized. Peripheral venous blood $(5 \mathrm{ml})$ was taken immediately, and left at room temperature for $20 \mathrm{~min}$. Then it was centrifuged at $1,006.2 \mathrm{xg}$ at $4^{\circ} \mathrm{C}$ for $10 \mathrm{~min}$, with a centrifugal radius of $10 \mathrm{~cm}$. The supernatant was collected and placed at $-80^{\circ} \mathrm{C}$ until testing. At the same time, $5 \mathrm{ml}$ of peripheral venous blood of healthy controls was collected, centrifuged and stored in a refrigerator at $-80^{\circ} \mathrm{C}$, and repeated freeze and thaw were avoided.

\section{Experiment steps}

Fluorescent quantitative polymerase chain reaction (RT-PCR) was used to detect the expression of mRNA levels of $I L-18$ and IL-35 in karyocytes in peripheral blood. Expression of mRNA levels of IL-18 and IL-35 in karyocytes in peripheral blood were detected by RT-PCR, and mononuclear cells in peripheral blood were isolated by Ficoll-Hypaque density gradient centrifugation at $400 \mathrm{x} g$ at $4^{\circ} \mathrm{C}$ for $40 \mathrm{~min}$. TRIzol extraction reagent was used to extract total RNA; an ultraviolet spectrophotometer was used to detect the purity and concentration; reverse transcription kits were used to transcribe RNA samples into cDNA in strict accordance with the instructions. ABI PRISM-7500 amplification instrument and SYBR Premix Ex Taq kit were used for RT-PCR reactions. For PCR amplification, the reaction system was: at $95^{\circ} \mathrm{C}$ for $10 \mathrm{~min}$, at $95^{\circ} \mathrm{C}$ for $15 \mathrm{sec}$, at $60^{\circ} \mathrm{C}$ for $1 \mathrm{~min}$, for 40 cycles. The melting curve was analyzed by increasing the temperature from 60 to $95^{\circ} \mathrm{C}$, with a temperature transition rate of $0.1^{\circ} \mathrm{C} / \mathrm{sec}$, three parallel reaction wells were set for each sample, and the experiment was repeated at least three times. The primers of the experiment were designed by Primer Premier 5.0 (Premier Biosoft) primer design software, and they were synthesized by Tianjin Saier Biotechnology Co., Ltd. Glyceraldehyde 3-phosphate dehydrogenase (GAPDH) was used as the internal reference, and the specific sequences are shown in Table I. In the results, the fluorescence signal is in the process of amplification of the cycle $\mathrm{Ct}$ value, and the inflection point which started from the background and entered the exponential growth phase corresponding to the number of cycles; $2^{-\Delta C t}$ was used to calculate the relative expression levels of mRNA of IL-18 and IL-35 of each sample.

The levels of $I L-18$ and $I L-35$ in the serum of the samples were detected by enzyme-linked immunosorbent assay (ELISA). Standard sample $(50 \mu \mathrm{l})$ was added into the wells coated with enzyme label. First, $40 \mu 1$ of sample diluent was added into the wells of the sample to be tested, and then $10 \mu 1$ of the sample (the dilution ratio of the sample was 5 times) was added, avoiding touching the wall of the wells during these steps, then the wells were shaken gently. The reaction wells were sealed with a sealing film, and then incubated in a water bath kettle or an incubator for $30 \mathrm{~min}$. After this, the sealing film was carefully removed, the liquid was discarded; and the wells were dried with absorbent paper, then each well was filled with washing solution. After $30 \mathrm{sec}$, this step was repeated five times and the wells were dried. Apart from the blank wells (the steps of the blank control wells were identical to the other steps, but enzyme-labeled reagent and sample were not added), $50 \mu \mathrm{l}$ of enzyme-labeled reagent was added into each well, next they were incubated at $37^{\circ} \mathrm{C}$ for $30 \mathrm{~min}$ and then they were washed. $50 \mu 1$ of substrate A and substrate B was added into each well, and the color was developed at $37^{\circ} \mathrm{C}$ for $15 \mathrm{~min}$ in the dark. Then $50 \mu 1$ of stop solution was added into each well, and zero setting was made with a blank well, and the absorbance (OD value) of each well was detected at the wavelength of $450 \mathrm{~nm}$ in $25 \mathrm{~min}$. The levels of IL-18 and IL-35 in the serum were calculated.

Experimental instruments and reagents. SYBR Premix Ex Taq kit, TRIzol extraction kit, cDNA reverse transcription kit (all from Takara Company), UV spectrophotometer (Shanghai Mapada Instrument Co., Ltd.), ABI PRISM-7500 amplification instrument (Shanghai Bajiu Industrial Co., Ltd.), IL-18 ELISA kit and IL-35 ELISA kit were from Moshake Biology Co., Ltd., BS-1101 enzyme-labeled instrument was from Beijing Linmao Technology Co., Ltd.

Observation indicators. The expression of platelet count (PLT), C-reactive protein (CRP), creatinine, and total bilirubin was detected. APACHE II score, SOFA score, infection site and 28-day mortality were recorded. The expression of mRNA of 
Table I. Sequences.

\begin{tabular}{lll}
\hline Gene & \multicolumn{1}{c}{ Upstream } & \multicolumn{1}{c}{ Downstream } \\
\hline IL-18 & 5'-CTTGAATCTAAATTATCAGTC-3' & 5'-GAAGATTCAAATTGCATCTTAT-3' \\
IL-35 & 5'-GCTCCCTACGTGCTCAATGTC-3' & 5'-AGGGTCGGGCTTGATGATGT-3' \\
GAPDH & 5'-GGAGCGAGATCCCTCCAAAAT-3' & 5'-GGCTGTTGTCATACTTCTCATGG-3'
\end{tabular}

IL, interleukin; GAPDH, glyceraldehyde 3-phosphate dehydrogenase.

Table II. Comparison of the clinical basic data in the three groups (mean $\pm \mathrm{SD}) /[\mathrm{n}(\%)]$.

\begin{tabular}{|c|c|c|c|c|c|}
\hline Clinical features & $\begin{array}{l}\text { Control group } \\
\qquad(\mathrm{n}=80)\end{array}$ & $\begin{array}{l}\text { Sepsis group } \\
\quad(n=96)\end{array}$ & $\begin{array}{c}\text { Sepsis TCP } \\
\text { group }(n=70)\end{array}$ & $\mathrm{F} / \chi^{2}$ value & P-value \\
\hline Sex & & & & 0.85 & 0.65 \\
\hline Male & $49(61.3)$ & $55(57.3)$ & $45(64.3)$ & & \\
\hline Female & $31(38.7)$ & $41(42.7)$ & $25(35.7)$ & & \\
\hline Age (years) & $64.20 \pm 6.81$ & $65.12 \pm 8.11$ & $66.21 \pm 10.12$ & 1.08 & 0.34 \\
\hline Hemoglobin (g/dl) & $13.93 \pm 3.13$ & $10.12 \pm 2.42^{\mathrm{a}}$ & $10.45 \pm 2.33^{\mathrm{a}}$ & 52.15 & $<0.01$ \\
\hline Albumin $(\mathrm{g} / \mathrm{dl})$ & $3.65 \pm 1.21$ & $3.03 \pm 0.78^{\mathrm{a}}$ & $2.32 \pm 0.62^{\mathrm{a}, \mathrm{b}}$ & 40.12 & $<0.01$ \\
\hline Creatinine (mg/dl) & $1.22 \pm 0.65$ & $1.51 \pm 0.87^{\mathrm{a}}$ & $1.94 \pm 1.03^{\mathrm{a}, \mathrm{b}}$ & 13.26 & $<0.01$ \\
\hline Total bilirubin (mg/dl) & $0.21 \pm 0.12$ & $0.50 \pm 0.20^{\mathrm{a}}$ & $0.65 \pm 0.31^{\mathrm{a}, \mathrm{b}}$ & 80.32 & $<0.01$ \\
\hline Platelet count $\left(\mathrm{x} 10^{9} / 1\right)$ & $186.11 \pm 21.31$ & $178.34 \pm 13.21^{\mathrm{a}}$ & $72.36 \pm 20.12^{\mathrm{a}, \mathrm{b}}$ & 654.3 & $<0.01$ \\
\hline Whole blood leukocyte count (x109/1) & $9.34 \pm 1.02$ & $10.45 \pm 1.32^{\mathrm{a}}$ & $10.32 \pm 1.41^{\mathrm{a}}$ & 19.19 & $<0.01$ \\
\hline Fibrinogen $(\mathrm{g} / \mathrm{l})$ & $3.47 \pm 1.00$ & $4.78 \pm 1.32^{\mathrm{a}}$ & $4.98 \pm 1.48^{\mathrm{a}}$ & 32.73 & $<0.01$ \\
\hline $\mathrm{CRP}(\mathrm{mg} / \mathrm{dl})$ & $4.23 \pm 3.01$ & $9.32 \pm 6.68^{\mathrm{a}}$ & $10.11 \pm 7.21^{\mathrm{a}}$ & 22.94 & $<0.01$ \\
\hline
\end{tabular}

${ }^{\mathrm{a}} \mathrm{P}<0.05$ compared with the control group; ${ }^{\mathrm{b}} \mathrm{P}<0.05$ compared with the sepsis group. CRP, C-reactive protein; TCP, thrombocytopenia.

IL-18 and IL-35 in karyocytes in peripheral blood and their expressions in the serum were observed. The correlation between IL-18, IL-35 and platelets in the serum of the patients with sepsis TCP was analyzed.

Statistical processing. SPSS 19.0 software system (IBM Corp.) was used to statistically analyze the experiment data. The enumeration data were expressed in the form of $[\mathrm{n}(\%)]$, Chi-square test was used in comparison between groups in this study. The measurement data were expressed in the form of mean $\pm \mathrm{SD}$, t-test was used in the comparison between two groups; variance analysis followed by LSD-t test was used in the comparison between groups, Pearson's correlation coefficient was used in the bivariate normal distribution data. At $\mathrm{P}<0.05$, the difference was statistically significant.

\section{Results}

Comparison of the clinical basic data in the three groups. There were no statistically significant differences in sex and age between the three groups $(\mathrm{P}>0.05)$. The differences in hemoglobin, albumin, creatinine, total bilirubin, platelet count, whole blood leukocyte count, fibrinogen and C-reactive protein (CRP) concentration between the three groups were statistically significant $(\mathrm{P}<0.05)$. There were significant differences in albumin, creatinine, total bilirubin and platelet count between the sepsis group and the sepsis TCP group $(\mathrm{P}<0.05)$ (Table II).

Comparison of infection site and organ damage and other baseline data of the patients in the sepsis group and the sepsis TCP group. There was no difference in APACHE II score and SOFA score between the patients in the sepsis group and the sepsis TCP group $(\mathrm{P}>0.05)$; there was no significant difference in the source of infection, the site of infection, the number of organ damage and the type of organ damage between the two groups $(\mathrm{P}>0.05)$; there were significant differences in presence and absence of shock, ICU mortality, and 28-day mortality between the two groups $(\mathrm{P}<0.05)$; the rate of patients with shock, ICU mortality and 28-day mortality in the sepsis group were lower than those in the sepsis TCP group (Table III).

Expression of mRNA of IL-18 and IL-35 in karyocytes in peripheral blood in the three groups. As shown in Fig. 1, the expression of mRNA of IL-18 in karyocytes in peripheral blood in the sepsis group and the sepsis TCP group was higher than that in the control group $(\mathrm{P}<0.05)$, and the expression of mRNA of IL-18 in the sepsis TCP group was higher than that in the sepsis group $(\mathrm{P}<0.05)$. Expression of mRNA of IL-35 in a karyocyte in peripheral blood in the sepsis group and the sepsis TCP group was higher than that in the control group 
Table III. Comparison of infection site and organ damage and other baseline data of the patients in the sepsis group and the sepsis TCP group $($ mean $\pm \mathrm{SD}) /[\mathrm{n}(\%)]$.

\begin{tabular}{|c|c|c|c|c|}
\hline Baseline data & $\begin{array}{l}\text { Sepsis group } \\
\quad(\mathrm{n}=96)\end{array}$ & $\begin{array}{l}\text { Sepsis TCP group } \\
\quad(\mathrm{n}=70)\end{array}$ & $\chi^{2} / \mathrm{t}$ value & P-value \\
\hline APACHE II score & $24.12 \pm 7.21$ & $22.79 \pm 8.99$ & 1.06 & 0.29 \\
\hline SOFA score & $12.76 \pm 4.27$ & $11.56 \pm 4.12$ & 1.82 & 0.07 \\
\hline Source of infection & & & 0.45 & 0.80 \\
\hline Gram negative bacteria & $39(40.6)$ & $27(38.6)$ & & \\
\hline Gram positive bacteria & $34(35.4)$ & $23(32.8)$ & & \\
\hline Others & $23(24.0)$ & $20(28.6)$ & & \\
\hline Site of infection & & & 0.40 & 1.00 \\
\hline Pulmonary infection & $31(32.3)$ & $21(30.0)$ & & \\
\hline Abdominal infection & $11(11.4)$ & $9(12.9)$ & & \\
\hline Blood infection & $10(10.4)$ & $8(11.4)$ & & \\
\hline Urinary tract infection & $12(12.5)$ & $10(14.3)$ & & \\
\hline Soft tissue infection & $9(9.4)$ & $7(10.0)$ & & \\
\hline Others & $23(24.0)$ & $15(21.4)$ & & \\
\hline Presence or absence of shock & & & 13.84 & $<0.01$ \\
\hline Yes & 14 (14.6) & $28(40.0)$ & & \\
\hline No & $82(85.4)$ & $42(60.0)$ & & \\
\hline The number of organ damage & & & 0.06 & 0.80 \\
\hline$\leq 2$ & $54(56.2)$ & $38(54.3)$ & & \\
\hline$>2$ & $42(43.8)$ & $32(45.7)$ & & \\
\hline Type of organ damage & & & 0.16 & 1.00 \\
\hline Arterial hypotension & $13(13.5)$ & $9(12.9)$ & & \\
\hline Arterial hypoxemia & $17(17.7)$ & $12(17.1)$ & & \\
\hline Acute lung injury & $12(12.5)$ & $8(11.4)$ & & \\
\hline Acute renal failure & $24(25.0)$ & $18(25.7)$ & & \\
\hline Acute respiratory failure & $16(16.7)$ & $13(18.6)$ & & \\
\hline Nerve injury & $14(14.6)$ & $10(14.3)$ & & \\
\hline ICU mortality & $5(5.2)$ & $14(20.0)$ & 8.74 & 0.003 \\
\hline 28-day mortality & $31(32.3)$ & $45(64.3)$ & 16.69 & $<0.01$ \\
\hline
\end{tabular}

TCP, thrombocytopenia; SOFA, sequential organ failure assessment; APACHE II, acute physiology and chronic health evaluation.

$(\mathrm{P}<0.05)$, the expression of mRNA of IL-35 in the sepsis TCP group was higher than that in the sepsis group $(\mathrm{P}<0.05)$.

Concentration of IL-18 and IL-35 in the serum in the three groups. The concentration of IL-18 and IL-35 in the serum in the three groups was detected and the results showed that the concentration of IL-18 in the serum in the sepsis group and the sepsis TCP group was higher than that in the control group $(\mathrm{P}<0.05)$; the concentration of IL-18 in the sepsis TCP group was higher than that in the sepsis group $(\mathrm{P}<0.05)$. The concentration of IL-35 in the serum in the sepsis group and the sepsis TCP group were higher than that in the control group $(\mathrm{P}<0.05)$; the concentration of IL-35 in the sepsis TCP group was higher than that in the sepsis group $(\mathrm{P}<0.05)$ (Fig. 2).

Correlation analysis between platelets and IL-18 and IL-35. Correlation between platelets and IL-18 and IL-35 was studied. Correlation analysis of the protein concentrations of IL-18 and
IL-35 in the serum in the sepsis TCP group and the platelet count of the patients was performed. Figs. 3 and 4 show that IL-18 and IL-35 are negatively correlated with platelets $(r=-0.8749,-0.6228, \mathrm{P}<0.001)$.

Correlation between serum $I L-18$ and $I L-35$. Correlation between IL-18 and IL-35 in serum was analyzed using Pearson's correlation coefficient (Figs. 5-7). There was a significant positive correlation between serum IL-18 and IL-35 in the control group, sepsis group, and sepsis TCP group $(\mathrm{r}=0.5124,0.5718$, $0.5511, \mathrm{P}<0.001)$.

\section{Discussion}

Sepsis is one of the serious complications of acute and critically ill patients with shock, burns and severe trauma in clinic, often leading to septic shock and multiple organ dysfunction syndrome, which poses a serious threat to human health (17). 

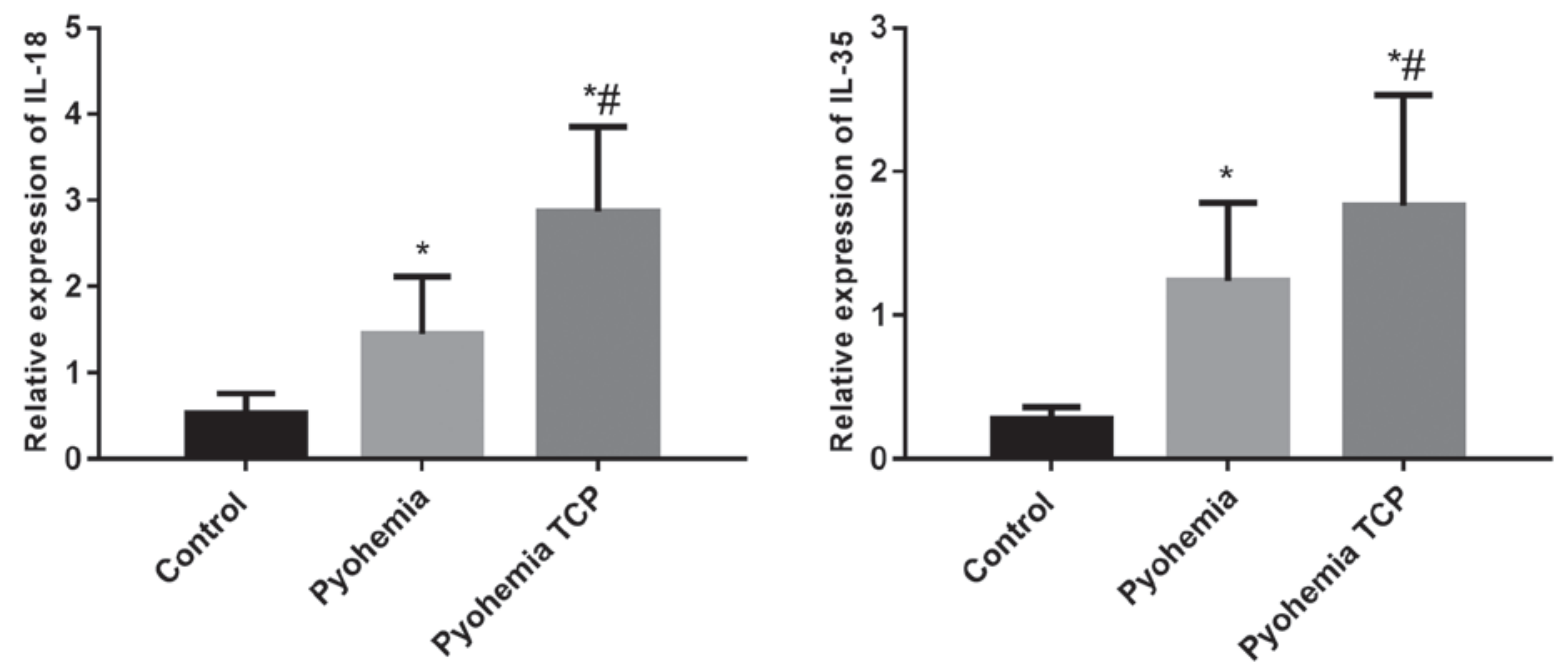

Figure 1. Expression of IL-18 and IL-35 mRNA in three groups of peripheral blood mononuclear cells. Expression of IL-18 mRNA in peripheral blood mononuclear cells of the sepsis and sepsis TCP groups was higher than that of the control group $(\mathrm{P}<0.05)$, and the mRNA expression of IL-18 in the sepsis TCP group was higher than that in the sepsis group $(\mathrm{P}<0.05)$. Expression of IL-35 mRNA in peripheral blood mononuclear cells of the sepsis and sepsis TCP groups was higher than that of the control group $(\mathrm{P}<0.05)$, and the mRNA expression of IL-35 in the sepsis TCP group was higher than that in the sepsis group $(\mathrm{P}<0.05) .{ }^{*} \mathrm{P}<0.05$ compared with the control group; ${ }^{*} \mathrm{P}<0.05$ compared with the sepsis group. TCP, thrombocytopenia; IL, interleukin.
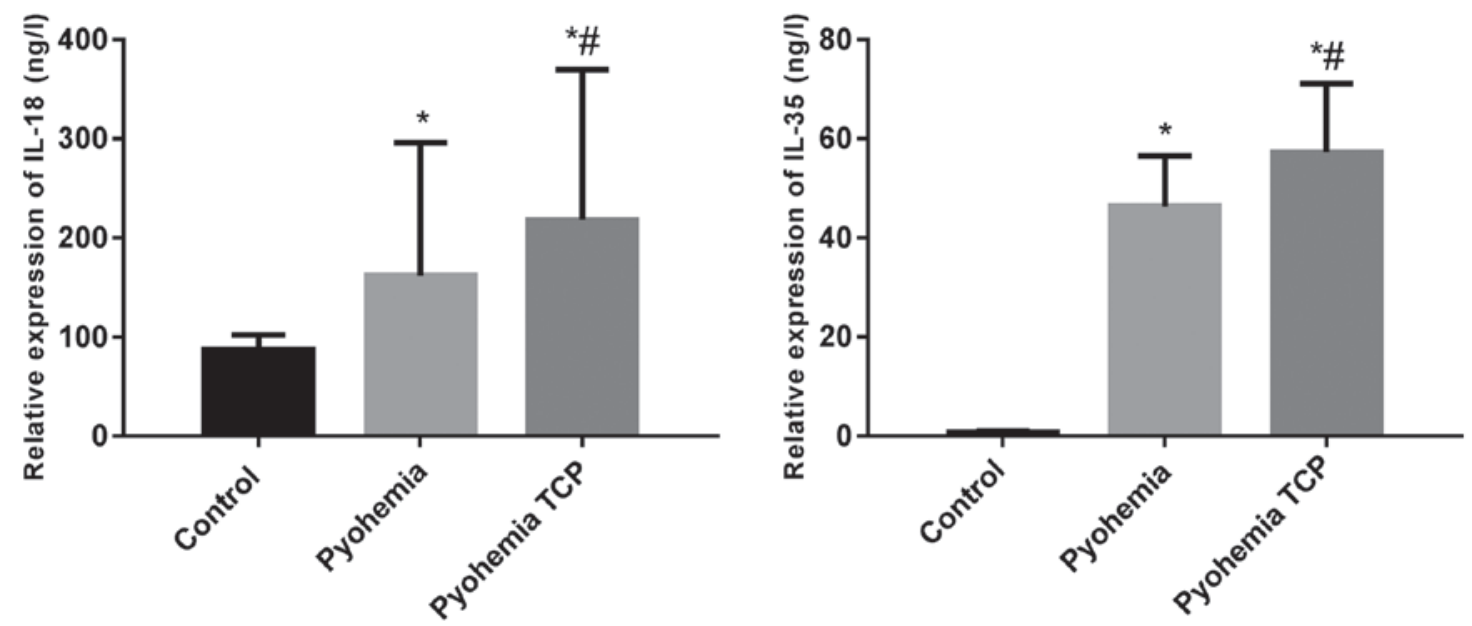

Figure 2. Concentration of IL-18 and IL-35 in the serum of three groups The serum IL-18 concentration in sepsis and sepsis TCP groups was higher than that in the control group $(\mathrm{P}<0.05)$. Concentration of IL-18 in the sepsis TCP group was higher than that in the sepsis group $(\mathrm{P}<0.05)$. Serum IL-35 concentration in the sepsis and sepsis TCP groups was higher than that in the control group $(\mathrm{P}<0.05)$, and the concentration of IL-35 in the sepsis TCP group was higher than that in the sepsis group $(\mathrm{P}<0.05)$. ${ }^{*} \mathrm{P}<0.05$ compared with the control group; ${ }^{*} \mathrm{P}<0.05$ compared with the sepsis group. TCP, thrombocytopenia; IL, interleukin.

Bone marrow is the most vulnerable. Inflammatory factors and bacterial toxins in the body inhibit hematopoietic cells in bone marrow (including megakaryocytes), causing thrombocytopenia by inhibiting megakaryocytes from producing platelets (18). Moreover, many ways facilitate platelet activation, thus activating the coagulation pathway, forming local microthrombus and increasing platelet consumption, which can cause thrombocytopenia; the severity of sepsis is closely related to the above processes $(19,20)$.

IL-18, a gene multi-dominant polypeptide regulator, is involved in growth and differentiation of cells and regulates the body's immune response (21). Study by Cui et al (22) reported that the expression level of IL-18 increases, and the expression of miR-130a decreases in plasma and miRNA of patients with severe sepsis and thrombocytopenia, suggesting that IL-18 and miR-130a may be involved in the pathophysiological process of severe sepsis accompanied by thrombocytopenia. As a member of the family of IL-12, IL-35 belongs to heterodimeric proteins and is made up of Ebi3 ( $\beta$-chain) and p35 ( $\alpha$-chain) (23). Studies have found that IL-35 can facilitate the secretion of IL-10 in rheumatoid arthritis and can inhibit the production of IL-17 and IFN- $\gamma$, thereby effectively inhibiting the inflammation in antigen-specificity immune response state; IL-35 plays an immunomodulatory role in a variety of inflammatory diseases (24). A study by Du et al (25) suggests that IL-35 can be used as a novel candidate biomarker for the diagnosis of early neonatal sepsis, and it is superior to PCT in the diagnosis.

This study found that when hemoglobin, albumin, creatinine, total bilirubin, platelet count, whole blood leukocyte count, fibrinogen and CRP were compared between the three groups, the differences were statistically significant $(\mathrm{P}<0.05)$. 


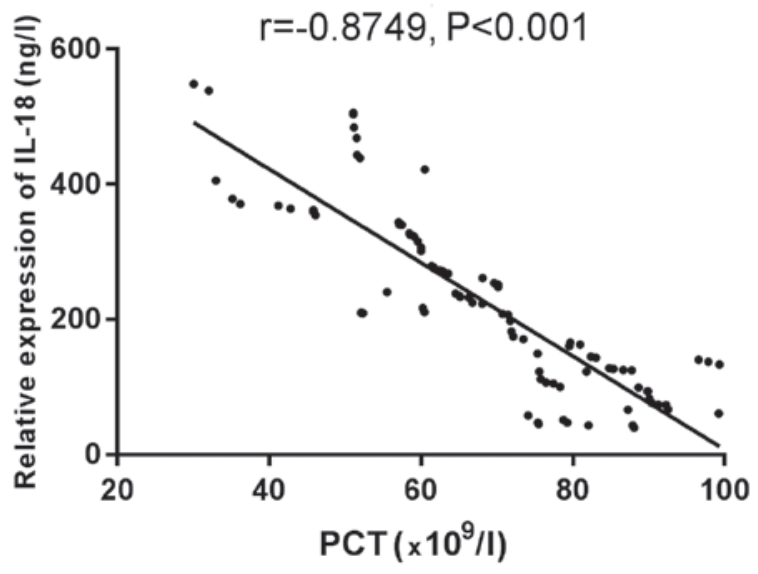

Figure 3. Correlation analysis between platelets and IL-18. Serum IL-18 in the sepsis TCP group was negatively correlated with platelets $(r=-0.8749$, $\mathrm{P}<0.001)$. TCP, thrombocytopenia; IL, interleukin.

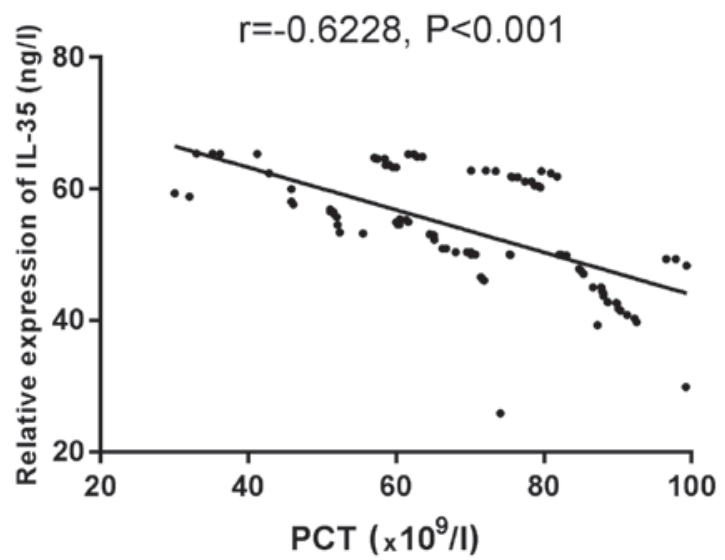

Figure 4. Correlation analysis between platelets and IL-35. Serum IL-35 in the sepsis TCP group was negatively correlated with platelets $(r=-0.6228$, $\mathrm{P}<0.001)$. TCP, thrombocytopenia; IL, interleukin.

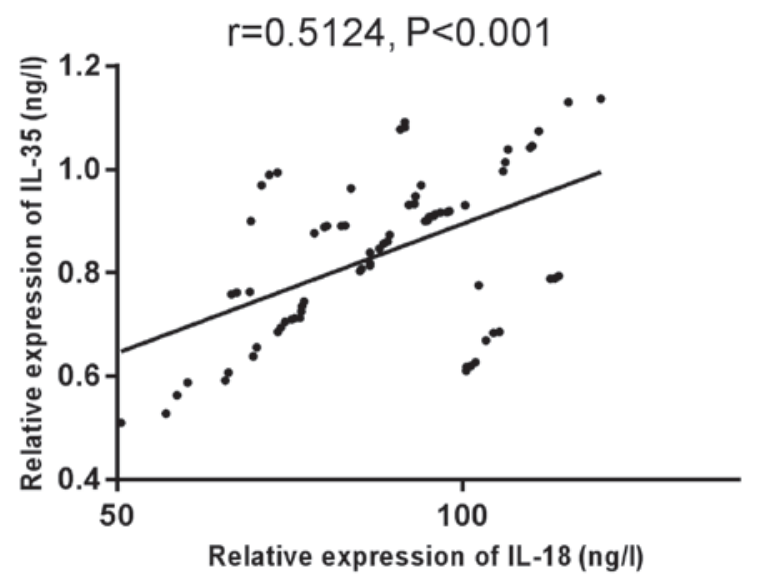

Figure 5. Correlation between serum IL-18 and serum IL-35 in the control group. According to Pearson's correlation coefficient analysis, serum IL-18 was significantly positively correlated with serum IL-35 $(r=0.5124, \mathrm{P}<0.001)$. IL, interleukin.

There was a significant difference in albumin, creatinine, total bilirubin and platelet count between the sepsis group and

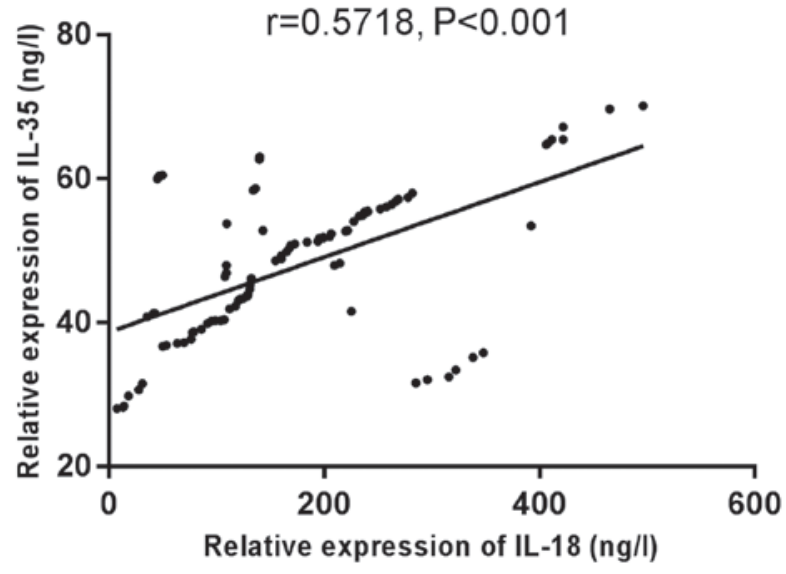

Figure 6. Correlation between serum IL-18 and serum IL-35 in the sepsis group. According to Pearson's correlation coefficient analysis, serum IL-18 was significantly positively correlated with serum IL-35 in the sepsis group $(\mathrm{r}=0.5718, \mathrm{P}<0.001)$. IL, interleukin.

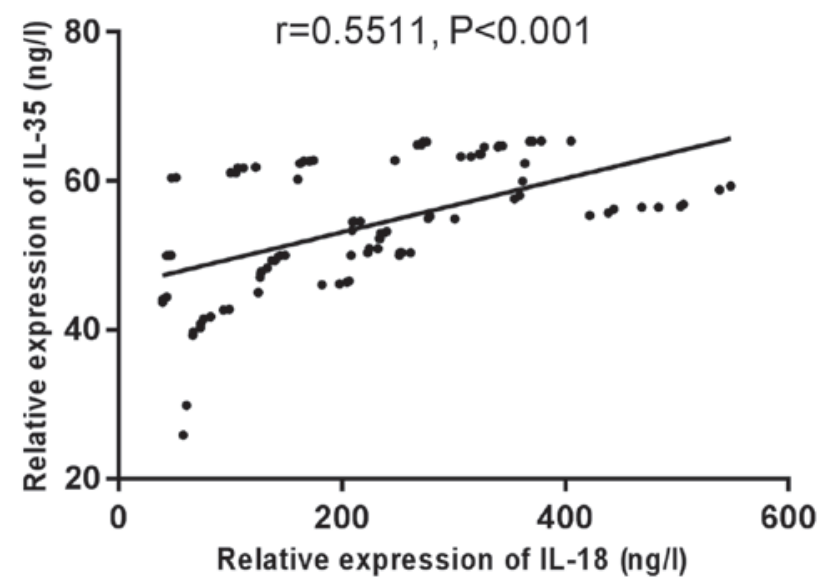

Figure 7. Correlation between serum IL-18 and serum IL-35 in sepsis TCP group. According to Pearson's correlation coefficient analysis, serum IL-18 was significantly positively correlated with serum IL-35 in the sepsis TCP group ( $\mathrm{r}=0.6159, \mathrm{P}<0.001)$. TCP, thrombocytopenia; IL, interleukin.

the sepsis TCP group. There was no difference in APACHE II score and SOFA score between the sepsis group and the sepsis TCP group; there was no significant difference in the source of infection, the infection site, the number of organ damage and the type of organ damage between the two groups $(\mathrm{P}>0.05)$; the number of patients with shock, ICU mortality and 28-day mortality in the sepsis group were lower than those in the sepsis TCP group. Oberholzer et al (26) found that the level of IL-18 in patients with sepsis was significantly higher than that in healthy people; the levels of IL-18 in patients with septic shock and patients with sepsis who died were higher than those in patients without shock and patients with sepsis who survived. Sun and Zhang (27) detected the level of IL-18 in patients with ICU sepsis in the first 3 days, and it was found that the severity and prognosis of patients with sepsis were closely related to the increase of level of IL-18. It is reported that the high expression of IL-18 in the serum may be an early predictive factor of death (28). IL-35 in plasma is associated with the severity of sepsis and can also be used as a warning factor of sepsis to predict illness condition (29). This study 
showed that the expression levels of mRNA of IL-18 and IL-35 in karyocytes in peripheral blood in the sepsis group and the sepsis TCP group were higher than those in the control group, and the expression levels of mRNA of IL-18 and IL-35 in the sepsis TCP group were higher than those in the sepsis group $(\mathrm{P}<0.05)$. By detecting the concentrations of IL-18 and IL-35 in the serum in the three groups, the results showed that the concentrations of IL-18 and IL-35 in the serum in the sepsis group and the sepsis TCP group were higher than those in the control group, and the concentrations of IL-18 and IL-35 in the sepsis TCP group were higher than those in the sepsis group. Related studies have found that the concentration of IL-35 in the serum of patients with sepsis is significantly higher than that in healthy people, suggesting that the expression level of IL-35 increases in patients with sepsis, and the concentration of IL-35 in patients with sepsis who die is significantly higher than that in survivors (30). Thrombocytopenia is one of the most common abnormalities in patients with severe sepsis (24). In this study, it is found that the concentration of IL-35 in patients with sepsis and thrombocytopenia is higher than that in patients with sepsis, which provides reference for future clinical research. Related literature reports that platelet counts in children with immune thrombocytopenic purpura have a negative correlation with serum IL-18 (31). Little is known about the correlation between IL-35 and platelet count. In the present study, the correlation analysis was on the concentrations of IL-18 and IL-35 in the serum in the sepsis TCP group and the platelets of patients. It was found that IL-18 and IL-35 are negatively correlated with platelets ( $r=-0.8749,-0.6228, \mathrm{P}<0.001)$. This was possibly caused by the death ligand in platelets being highly expressed due to inflammatory factors, which enhance the killing effect of lymphocytes and cause apoptosis of platelets, thereby causing a decrease in platelet count. The specific mechanism remains to be further investigated. It has been reported that elevated serum IL-35 levels in patients with sepsis are associated with logistic organ dysfunction (LOD) or simplified acute physiology score (SAPS II) and are associated with inflammatory markers (32). In this study, the correlation between serum IL-18 and IL-35 was analyzed, and serum IL-18 was found to be significantly positively correlated with IL-35. This indicates that IL-35 may be involved in the regulation of IL-18. However, there is currently no research in this direction, and more investigations are needed.

This study investigated the expression and clinical significance of IL-18 and IL-35 in the serum of patients with sepsis TCP, and confirmed that there is a correlation between the expression of IL-18 and IL-35 and platelets in the serum of patients with sepsis TCP, which has certain clinical significance. However, since this is a retrospective study, all confounding factors that may exist in critically ill patients in different time cannot be controlled.

In conclusion, IL-18 and IL-35 are negatively correlated with the degree of thrombocytopenia in patients with sepsis, which indicates that these two factors play an important role in the pathogenetic process of sepsis.

\section{Acknowledgements}

Not applicable.

\section{Funding}

No funding was received.

\section{Availability of data and materials}

The datasets used and/or analyzed during the present study are available from the corresponding author on reasonable request.

\section{Authors' contributions}

MZ conceived the study and drafted the manuscript. MZ and XR detected CRP and NPY concentrations. ML and SW performed some of the experiments. All authors read and approved the final manuscript.

\section{Ethics approval and consent to participate}

The study was approved by the Ethics Committee of Jinan Central Hospital Affiliated to Shandong University (Jinan, China). Patients who participated in this research had complete clinical data. Patients and their family signed an informed consent.

\section{Patient consent for publication}

Not applicable.

\section{Competing interests}

The authors declare that they have no competing interests.

\section{References}

1. Dewitte A, Lepreux S, Villeneuve J, Rigothier C, Combe C, Ouattara A and Ripoche J: Blood platelets and sepsis pathophysiology: A new therapeutic prospect in critically [corrected] ill patients? Ann Intensive Care 7: 115, 2017.

2. Fleischmann C, Scherag A, Adhikari NK, Hartog CS, Tsaganos T, Schlattmann P, Angus DC and Reinhart K; International Forum of Acute Care Trialists: Assessment of global incidence and mortality of hospital-treated sepsis. Current estimates and limitations. Am J Respir Crit Care Med 193: 259-272, 2016.

3. Larkin CM, Santos-Martinez MJ, Ryan T and Radomski MW: Sepsis-associated thrombocytopenia. Thromb Res 141: 11-16, 2016.

4. Yaguchi A, Lobo FL, Vincent JL and Pradier O: Platelet function in sepsis. J Thromb Haemost 2: 2096-2102, 2004.

5. Vandijck DM, Blot SI, De Waele JJ, Hoste EA, Vandewoude KH and Decruyenaere JM: Thrombocytopenia and outcome in critically ill patients with bloodstream infection. Heart Lung 39: 21-26, 2010

6. Xu R, Lin F, Bao C, Huang H, Ji C, Wang S, Jin L, Sun L, Li K, Zhang Z, et al: Complement 5a receptor-mediated neutrophil dysfunction is associated with a poor outcome in sepsis. Cell Mol Immunol 13: 103-109, 2016.

7. Li MF, Li XL, Fan KL, Yu YY, Gong J, Geng SY, Liang YF, Huang L, Qiu JH, Tian XH, et al: Platelet desialylation is a novel mechanism and a therapeutic target in thrombocytopenia during sepsis: An open-label, multicenter, randomized controlled trial. J Hematol Oncol 10: 104, 2017.

8. Yeaman MR and Bayer AS: Staphylococcus aureus, platelets, and the heart. Curr Infect Dis Rep 2: 281-298, 2000.

9. Claushuis TA, van Vught LA, Scicluna BP, Wiewel MA, Klein Klouwenberg PM, Hoogendijk AJ, Ong DS, Cremer OL, Horn J, Franitza M, et al; Molecular Diagnosis and Risk Stratification of Sepsis Consortium: Thrombocytopenia is associated with a dysregulated host response in critically ill sepsis patients. Blood 127: 3062-3072, 2016. 
10. Kwak A, Lee Y, Kim H and Kim S: Intracellular interleukin (IL)-1 family cytokine processing enzyme. Arch Pharm Res 39: 1556-1564, 2016.

11. Eidt MV, Nunes FB, Pedrazza L, Caeran G, Pellegrin G, Melo DA, Possuelo L, Jost RT, Dias HB, Donadio MV, et al: Biochemica and inflammatory aspects in patients with severe sepsis and septic shock: The predictive role of IL-18 in mortality. Clin Chim Acta 453: 100-106, 2016.

12. Okuhara Y, Yokoe S, Iwasaku T, Eguchi A, Nishimura K, Li W, Oboshi M, Naito Y, Mano T, Asahi M, et al: Interleukin-18 gene deletion protects against sepsis-induced cardiac dysfunction by inhibiting PP2A activity. Int J Cardiol 243: 396-403, 2017.

13. Li M, Eck1 J, Geiger C, Schendel DJ and Pohla H: A novel and effective method to generate human porcine-specific regulatory $\mathrm{T}$ cells with high expression of IL-10, TGF- $\beta 1$ and IL-35. Sci Rep 7: 3974, 2017.

14. Gao P, Su Z, Lv X and Zhang J: Interleukin-35 in asthma and its potential as an effective therapeutic agent. Mediators Inflamm 2017: 5931865, 2017.

15. Sha X, Meng S, Li X, Xi H, Maddaloni M, Pascual DW, Shan H, Jiang X, Wang $\mathrm{H}$ and Yang XF: Interleukin-35 inhibits endothelial cell activation by suppressing MAPK-AP-1 pathway. J Biol Chem 290: 19307-19318, 2015.

16. Levy MM, Fink MP, Marshall JC, Abraham E, Angus D, Cook D, Cohen J, Opal SM, Vincent JL and Ramsay G; SCCM/ ESICM/ACCP/ATS/SIS: 2001 SCCM/ESICM/ACCP/ATS/SIS International Sepsis Definitions Conference. Crit Care Med 31: 1250-1256, 2003.

17. Vardas K, Apostolou K, Briassouli E, Goukos D, Psarra K, Botoula E, Tsagarakis S, Magira E, Routsi C, Nanas S, et al: Early response roles for prolactin cortisol and circulating and cellular levels of heat shock proteins 72 and $90 \alpha$ in severe sepsis and SIRS. BioMed Res Int 2014: 803561, 2014.

18. Tang G, Wang XM, Meng JX, Luan CL, Chen JF, Wu YQ, Zhang XN and He ZY: Efficacy of recombinant human thrombopoietin and recombinant human interleukin 11 for treatment of chemotherapy induced thrombocytopenia in acute myeloid leukaemia patients. Zhongguo Shi Yan Xue Ye Xue Za Zhi 26 234-238, 2018 (In Chinese)

19. Semple JW and Freedman J: Platelets and innate immunity. Cell Mol Life Sci 67: 499-511, 2010.

20. Yeaman MR: Platelets in defense against bacterial pathogens. Cell Mol Life Sci 67: 525-544, 2010
21. Yan Y, Jiang W, Liu L, Wang X, Ding C, Tian Z and Zhou R: Dopamine controls systemic inflammation through inhibition of NLRP3 inflammasome. Cell 160: 62-73, 2015.

22. Cui YL, Wang B, Gao HM, Xing YH, Li J, Li HJ, Lin Z and Wang YQ: Interleukin-18 and miR-130a in severe sepsis patients with thrombocytopenia. Patient Prefer Adherence 10: 313-319, 2016.

23. Vignali DA and Kuchroo VK: IL-12 family cytokines: Immunological playmakers. Nat Immunol 13: 722-728, 2012.

24. Kochetkova I, Golden S, Holderness K, Callis G and Pascual DW: IL-35 stimulation of $\mathrm{CD} 39^{+}$regulatory $\mathrm{T}$ cells confers protection against collagen II-induced arthritis via the production of IL-10. J Immunol 184: 7144-7153, 2010

25. Du WX, He Y, Jiang HY, Ai Q and Yu JL: Interleukin 35: A novel candidate biomarker to diagnose early onset sepsis in neonates. Clin Chim Acta 462: 90-95, 2016.

26. Oberholzer A, Steckholzer U, Kurimoto M, Trentz O and Ertel W: Interleukin-18 plasma levels are increased in patients with sepsis compared to severely injured patients. Shock 16: 411-414, 2001.

27. Sun RQ and Zhang SL: The value of serum interleukin-18 and 10 in the evaluation of severity and prognosis in the early stage of sepsis. Zhongguo Wei Zhong Bing Ji Jiu Yi Xue 23: 299-301, 2011 (In Chinese)

28. Emmanuilidis K, Weighardt H, Matevossian E, Heidecke CD, Ulm K, Bartels H, Siewert JR and Holzmann B: Differential regulation of systemic IL-18 and IL-12 release during postoperative sepsis: High serum IL-18 as an early predictive indicator of lethal outcome. Shock 18: 301-305, 2002.

29. Lally KP, Cruz E and Xue H: The role of anti-tumor necrosis factor-alpha and interleukin-10 in protecting murine neonates from Escherichia coli sepsis. J Pediatr Surg 35: 852-855, 2000.

30. Zhao HQ, Li WM, Lu ZQ, Sheng ZY and Yao YM: The growing spectrum of anti-inflammatory interleukins and their potential roles in the development of sepsis. J Interferon Cytokine Res 35: 242-251, 2015.

31. Shaheen IA, Botros SKA and Morgan DS: Detection of expression of IL-18 and its binding protein in Egyptian pediatric immune thrombocytopenic purpura. Platelets 25: 193-196, 2014.

32. Cao J, Xu F, Lin S, Tao X, Xiang Y, Lai X and Zhang L: IL-35 is elevated in clinical and experimental sepsis and mediates inflammation. Clin Immunol 161: 89-95, 2015.

This work is licensed under a Creative Commons

Attribution-NonCommercial-NoDerivatives 4.0 International (CC BY-NC-ND 4.0) License. 